\title{
Chemiluminescence of the Reaction System Ce(IV) - Non-Steroidal Anti-Inflammatory Drugs Containing Europium(III) Ions and its Application to the Determination of Naproxen in Pharmaceutical Preparations and Urine
}

\author{
Małgorzata Kaczmarek
}

Received: 17 November 2010 / Accepted: 4 July 2011 /Published online: 13 July 2011

(C) The Author(s) 2011. This article is published with open access at Springerlink.com

\begin{abstract}
The chemiluminescence (CL) of oxidation of nonsteroidal anti-inflammatory drugs (NSAIDs) by Ce(IV) ions, was recorded in the presence and absence europium(III) ions, in solution of $\mathrm{pH} \sim 4$ of solution. Kinetic curves and $\mathrm{CL}$ emission spectra of the all studied systems were discussed. CL of measurable intensity was observed in the Ce(IV)-NP-Eu (III) reaction system only in acidic solutions. The CL spectrum rcegistered for this system shows emission bands, typical of Eu(III) ions, with maximum at $\lambda \sim 600 \mathrm{~nm}$. The chemiluminescent method, based on $\mathrm{Eu}(\mathrm{III})$ emission in reaction system of NP-Ce(IV)-Eu(III) in acid solution was therefore used for the determination of naproxen in mixture of non-steroidal anti-inflammatory drugs.
\end{abstract}

Keywords Chemiluminescence $\cdot$ Europium $\cdot$ Non-steroidal anti-inflammatory drugs

\section{Introduction}

Naproxen(NP), ibuprofen(IB) and indomethacin (IM) are non-steroidal anti-inflammatory drugs (NSAID). Chemically, $\mathrm{NP}$ and IB belong to the 2-arylpropionic acid family, whereas IM belongs to the class of arylacetic acid. The NSAID as a group are diverse in chemical structure but are consistent in their ability to inhibit the enzyme cyclooxygenase, regarded as a marker for inflammation [1]. The complexation

M. Kaczmarek ( $\bowtie)$

Department of Rare Earths, Faculty of Chemistry, Adam

Mickiewicz University,

Grunwaldzka 6,

60-780 Poznań, Poland

e-mail: mkaczmar@amu.edu.pl processes of naproxen(NP) or ibuprofen(IB) or indomethacin (IM) with lanthanide ions depend of $\mathrm{pH}$ values. In acidic solution, the degree of complexation is small [2]. The trivalent lanthanide ions, especially $\mathrm{Eu}(\mathrm{III})$ and $\mathrm{Tb}(\mathrm{III})$, display spectroscopic properties of high photoluminescence efficiencies, long excited-state lifetimes band narrow emission spectra, all of which make them be widely used as analytical luminescent probes for a variety of chemical and biological applications [3-5].

Chemiluminescence can be achieved by direct reactions or by energy-transfer mechanisms. The CL phenomenon can be applied as detection technique for the monitoring of a wide variety of compounds in diverse fields, such as biomedical, environmental and can be considered as an alternative to other detection modes such as: UV/Vis spectroscopy, fluorescence [6]. In this work, the use of sensitized chemiluminescence of lanthanide ions for determination of naproxen in mixture of NSAIDs is studied. It was observed that only the CL signal of the $\mathrm{Ce}(\mathrm{IV})$ - Naproxen system was significantly increased in the presence of $\mathrm{Eu}(\mathrm{III})$ ions.

\section{Experimental}

Ultra weak photon emission was recorded with the use of the earlier described equipment [7]. The fluorescence spectra were recorded using F-7000 HITACHI spectrofluorimeter.

Chemicals

All chemicals used were of analytical reagent grade and doubly distilled water was used throughout the experi- 
ments. Naproxen sodium and indomethacin were from Sigma, ibuprofen sodium was from Fluka.

Their stock standard solutions $\left(2 \times 10^{-3} \mathrm{molL}^{-1}\right)$ were prepared by dissolving appropriate amount of naproxen sodium and ibuprofen sodium in water and diluting to $100 \mathrm{ml}$ with water. A stock standard solution of indomethacin $\left(6 \times 10^{-4} \mathrm{molL}^{-1}\right)$ was prepared by dissolving an appropriate amount of IM with $0.1 \mathrm{molL}^{-1}$ hydrochloric acid and then diluting to $100 \mathrm{~mL}$ with water. Working standard solutions of naproxen sodium were prepared of diluted the stock solution with water.

\section{Optimization of Experimental Conditions}

The optimum conditions for the naproxen determinations were carried out using the $1 \times 10^{-6} \mathrm{molL}^{-1}$ concentration of NP. The effect of $\mathrm{Ce}(\mathrm{IV})$ concentration on the $\mathrm{CL}$ reaction was examined in the range of $5.0 \times 10^{-4}$ to $4.0 \times 10^{-3}$ $\mathrm{molL}^{-1}$ in $0.015,0.025,0.05,0.15$ or $0.3 \mathrm{molL}^{-1} \mathrm{H}_{2} \mathrm{SO}_{4}$. The most integrated CL light sum was obtained when the concentration of $\mathrm{Ce}(\mathrm{IV})$ was $2.0 \times 10^{-3} \mathrm{~mol} \mathrm{~L}^{-1}$ in 0.015 $\mathrm{molL}^{-1} \mathrm{H}_{2} \mathrm{SO}_{4}$. For the NP-Ce(IV)-Eu(III) system, the optimum concentration of europium(III) ions, using the following range of concentrations $1.0 \times 10^{-4}-1.0 \times 10^{-2}$ molL ${ }^{-1}$ was determined. In the case of concentration of $\mathrm{Eu}$ (III) ions above $1.0 \times 10^{-3} \mathrm{molL}^{-1}$ the CL light intensity sums did not change, so as the optimal concentration of $\mathrm{Eu}$ (III) ions for the determination of NP $2.0 \times 10^{-3} \mathrm{~mol} \mathrm{~L}^{-1}$ was chosen.

\section{Measurement Procedure}

All of the chemiluminescence studies were performed in the same manner. Solution of cerium(IV) ions was added to solutions containing NSAID ( $1 \mathrm{~mL}$ solutions of appropriate concentrations) or NSAID and $\mathrm{Eu}(\mathrm{III})$ ions. The experiments were conducted in acidic solutions ( $\mathrm{pH} \sim 4)$. The total volume was $4 \mathrm{~mL}$. The determination of naproxen in water, pharmaceutical preparations was carried out measuring the CL light intensity sums of the reaction systems applying the cut-off filters method, with the use of a filter transmitting emission of $\lambda>585 \mathrm{~nm}$, which was placed between the photomultiplier and the measurement cell. CL light intensity sums were calculated as the area under these curves [4].

\section{Sample Preparation}

Tablets Not less than 10 tablets were weighed and finely powdered. Specific amounts of analyte were weighed accurately, dissolved in water in a small beaker. The solution was filtered, and the residue was washed with water several times. Then it was transferred into a
$250 \mathrm{~mL}$ calibrated flask and diluted to the specified volume with water. Working solutions were prepared by appropriate dilution of this sample solution so that the final analytic concentrations were within the working range.

Ointment Accurately weighed out amount of the ointment was dissolved in water $\left(40{ }^{\circ} \mathrm{C}\right)$ and $1 \mathrm{~mL} 0.1 \mathrm{molL}^{-1} \mathrm{NaOH}$ while vigorously mixing. Next the solution was cooled in a refrigerator, in order to separate from vaseline, and transferred into a $100 \mathrm{ml}$ calibrated flask and diluted to volume with water. The final concentration of NP was within the working range.

\section{Urine}

Urine samples were obtained from two healthy volunteers. Known amounts of standard solutions of naproxen were introduced into $1 \mathrm{~mL}$ of fresh urine samples. The typical naproxen urinary concentration was $0.2-20 \mu \mathrm{g} / \mathrm{ml}$ [8]. This urine sample was mixed with a $10 \mathrm{~mL}$ of $0.1 \mathrm{molL}^{-1} \mathrm{Ba}$ $(\mathrm{OH})_{2}$ solution and a $9 \mathrm{~mL}$ of $0.1 \mathrm{molL}^{-1} \mathrm{ZnSO}_{4}$ solution in order to remove protein and reducing substances $[9,10]$. The resulting solution was diluted to $50 \mathrm{~mL}$ with doubly distilled water and centrifuged at 3000 for $15 \mathrm{~min}$. The supernatant solution was stored and maintained below $5{ }^{\circ} \mathrm{C}$. For analysis $1 \mathrm{ml}$ of solution was used.

\section{Results and Discussion}

Effect of Presence of the Europium(III) Ions on the CL Intensity of the Ce(IV)-NSAID Systems

The chemiluminescence of systems containing NP or IB or $\mathrm{IM}$ and $\mathrm{Ce}(\mathrm{IV})$ ions as oxidizer in solution at $\mathrm{pH} \sim 4$ in the absence and in the presence europium(III) ions were studied. Chemiluminescence in the system NSAID-Ce(IV) was obtained, when the concentration of NSAID was higher than $2 \times 10^{-7} \mathrm{molL}^{-1}$ for NP and $4 \times 10^{-3} \mathrm{molL}^{-1}$ for IB and $2 \times 10^{-4} \mathrm{molL}^{-1}$ for IM. For all systems the course of the kinetic curves of CL were similar, with maximum after initiation of the reaction by introducing $\mathrm{Ce}$ (IV) ions. The emission at the level of the background was obtained in about $30 \mathrm{~s}$ after the reaction initiation. Introduction of $\mathrm{Eu}(\mathrm{III})$ ions into the system NSAID-Ce (IV) resulted in a strong increase in the emission intensity only in the system containing naproxen without a change in the kinetic curve character (curves 3 and 4 in Fig. 1). The intensity of CL of the systems IB-Ce(IV) and IB-Ce(IV)-Eu (III) or IM-Ce(IV) and IM-Ce(IV)-Eu(III) were the same. 


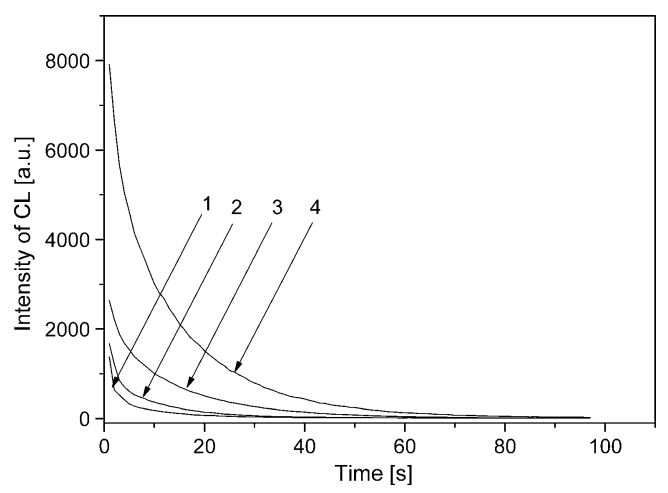

Fig. 1 The kinetic curves of CL decay in the NP-Ce(IV) system versus the concentration of NP: $6 \times 10^{-7} \mathrm{molL}^{-1}$ (curve 1); $2 \times 10^{-6} \mathrm{molL}^{-1}$ (curve 2 ) and NP-Ce(IV)-Eu(III) system versus the concentration of NP: $6 \times 10^{-7} \mathrm{molL}^{-1}$ (curve 3 ); $2 \times 10^{-6} \mathrm{molL}^{-1}$ (curve 4). The concentration of $\mathrm{Eu}(\mathrm{III})$ ions was $2 \times 10^{-3} \mathrm{molL}^{-1}$; the initial concentration of $\mathrm{Ce}$ (IV) was $2 \times 10^{-3} \mathrm{molL}^{-1}, \mathrm{pH} \sim 4$

The kinetics of the chemiluminescence decay of NP-Ce(IV) and NP-Ce(IV) - Eu(III) were monoexponential.

Spectral analysis of the chemiluminescence in the systems studied was performed using the method of cutoff filters as described earlier [11]. The spectra show a broad emission band in the range 400-600 $\mathrm{nm}$, with a maximum at $\lambda \sim 450 \mathrm{~nm}$ for NP and $480 \mathrm{~nm}$ for IM or $420 \mathrm{~nm}$ for IB, which is typical of the CL systems with the compounds containing excited carbonyl groups as emitters [12]. The spectral distribution of CL of NP-Ce(IV)-Eu(III) system dependent on the concentration of europium(III) ions. The spectral distribution, observed for the molar ratio Eu: $\mathrm{NP}=10: 1$, shows a broad band at $450 \mathrm{~nm}$ and a second band centered at $\lambda=600 \mathrm{~nm}$ (spectrum 2 in Fig. 2) corresponding to the ${ }^{5} \mathrm{D}_{0} \rightarrow{ }^{7} \mathrm{~F}_{1}$ and ${ }^{5} \mathrm{D}_{0} \rightarrow{ }^{7} \mathrm{~F}_{2}$ transition of the $\mathrm{Eu}(\mathrm{III})$ ion [13]. For higher molar ratio (Eu: NP above 100: 1) the dominant band is band typical for $\mathrm{Eu}(\mathrm{III})$ with a maximum at $\lambda \sim 600 \mathrm{~nm}$ (spectrum 4 in Fig. 2). This means

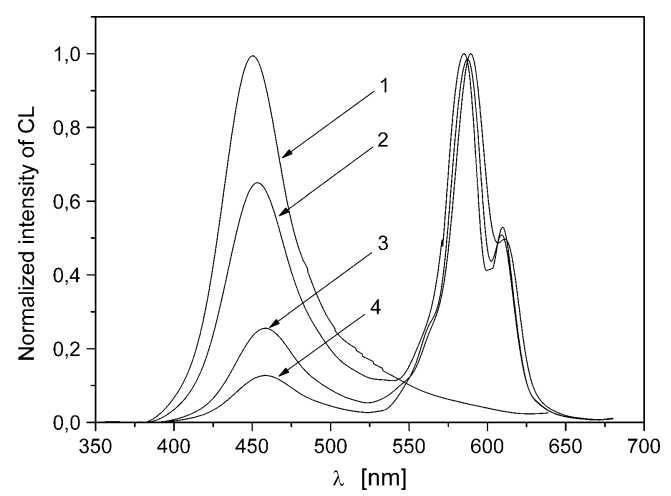

Fig. 2 The normalized spectral distribution of CL of the systems: NP$\mathrm{Ce}(\mathrm{IV})$ (spectrum 1) and NP-Ce(IV)-Eu(III) versus the molar ratio $\mathrm{Eu}$ (III): $\mathrm{NP}=10: 1$ (spectrum 2); 40: 1 (spectrum 3) and 100: 1 (spectrum 4). The concentration of NP was $1 \times 10^{-5} \mathrm{molL}^{-1}$; the initial concentration of $\mathrm{Ce}(\mathrm{IV})$ was $2 \times 10^{-3} \mathrm{molL}^{-1}, \mathrm{pH} \sim 4$ that the presence of the lanthanide ion is responsible for the increase in the CL intensity of NP-Ce(IV)-Eu(III) system.

In order to identify the role of the lanthanide ion in the reaction mixture NP-Ce(IV)-Eu(III), the process of $\mathrm{Ln}(\mathrm{III})$ complexation with $\mathrm{NP}$ in the $\mathrm{pH}$ range about 4-5 was studied. In the investigated $\mathrm{pH}$ region for all of the molar ratios used $(\mathrm{Eu}: \mathrm{NP}=10: 1 ; 40: 1$ and 100:1) the luminescence of $\mathrm{Eu}(\mathrm{III})$ was not observed, applying $\lambda_{\text {ex }}$ typical for NP, i.e.: $270 \mathrm{~nm}, 317 \mathrm{~nm}$ and $327 \mathrm{~nm}$. The recorded luminescence spectra show only one large unstructured band centered at around $353 \mathrm{~nm}$ (spectra 1, 2, 3 in Fig. 3), typical for this drug [14]. Using $\lambda_{\mathrm{ex}}=394 \mathrm{~nm}$ (typical for Eu (III) ions) the same luminescence spectrum (spectrum 4 in Fig. 3) as in the case of $\mathrm{EuCl}_{3}$ solution was obtained, which is typical for uncomplexed $\mathrm{Eu}(\mathrm{III})$ ions [11]. This indicates that the complex formation did not occur place in the chemiluminescent reaction system NP-Ce(IV)-Eu(III).

As follows from Fig. 1 the presence of $\mathrm{Eu}$ (III) ions have no effect on the rate of the naproxen oxidation with cerium (IV) ions. In the chemiluminescent experimental conditions europium(III) ions are uncomplexed and because of that a ligand to metal transfer process cannot appear (Fig. 3). The presence of europium(III) bands in the CL spectrum of the NP-Ce(IV)-Eu(III) system indicates that the excitation of $\mathrm{Eu}(\mathrm{III})$ ions in the reaction mixture is a result of the energy transfer process from the excited product of NP oxidation to the uncomplexed $\mathrm{Eu}(\mathrm{III})$ ions.

Oxidative decarboxylation of substituted phenylacetic acids can be mediated by metallic and nonmetallic oxidants or by electrolytic means [15]. When naproxen was treated with cerium (IV) or peroxodisulfate, the product pattern was similar to that from photolysis [16]. The major photoproducts obtained by irradiation of the drug under aerobic conditions are 6-methoxy-2-(1-hydroxyethyl)naphthalene and 6-methoxy-2-acetyl-naphthalene, and a

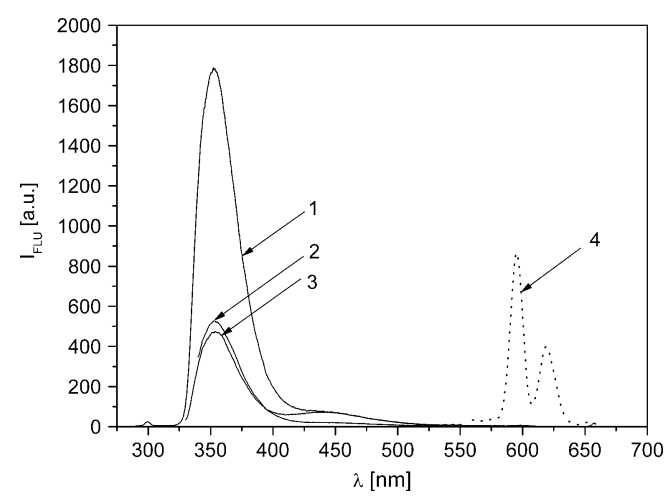

Fig. 3 The fluorescence spectrum of aqueous solution containing NP and $\mathrm{Eu}(\mathrm{III})$ ions at $\mathrm{pH}$ value $4-5$. The concentrations of NP was $4 \times$ $10^{-4} \mathrm{molL}^{-1}$ and $\mathrm{Eu}(\mathrm{III})$ was $1 \times 10^{-2} \mathrm{molL}^{-1}$ and $\lambda_{\text {exc }}$ were: $270 \mathrm{~nm}$ (spectrum 1); $318 \mathrm{~nm}$ (spectrum 2); $327 \mathrm{~nm}$ (spectrum 3) and $394 \mathrm{~nm}$ (spectrum 4); $\mathrm{pH} \sim 4$ 
Table 1 Determination of naproxen in commercial formulations with the proposed CL method $(n=5)$

\begin{tabular}{llcr}
\hline Drug sample & $\begin{array}{l}\text { Label } \\
\text { Amount }(\mathrm{mg})\end{array}$ & $\begin{array}{l}\text { Found by proposed } \\
\text { method (mg } \pm \text { S.D.) }\end{array}$ & Recovery [\%] \\
\hline APO-NAPROXEN & $250 \mathrm{mg}$ & $249 \pm 3$ & $99.6 \pm 1.2$ \\
ALEVE & $220 \mathrm{mg}$ & $223 \pm 4$ & $101.4 \pm 1.8$ \\
NAPROXEN & $500 \mathrm{mg}$ & $495.5 \pm 7$ & $99.1 \pm 1.4$ \\
NAPROXEN & $250 \mathrm{mg}$ & $255.3 \pm 3$ & $102.1 \pm 1.2$ \\
NAPROXEN EMO gel & $100 \mathrm{mg} \mathrm{g}^{-1}$ & $101.8 \pm 2 \mathrm{mg} \mathrm{g}^{-1}$ & $101.8 \pm 2$ \\
\hline
\end{tabular}

small amount of 6-methoxy-2-ethyl-naphthalene. The 6methoxy-2-acetyl-naphthalene shows the emission band centered at around $440 \mathrm{~nm}$ [17], which correspond to the chemiluminescent spectrum.

\section{Analytical Application}

The reaction mixture of NP-Ce(IV)-Eu(III) was used for the determination of the naproxen concentration, with applying the cut-off filters method. A linear dependence of the CL light intensity sums of the reaction system on the NP concentration, with the use of a filter transmitting emission of $\lambda>585 \mathrm{~nm}$, was obtained in the NP concentration range of $4 \times 10^{-8} \mathrm{molL}^{-1}(9 \mathrm{ng} / \mathrm{mL})$ to $2 \times 10^{-6} \mathrm{molL}^{-1}(460 \mathrm{ng} /$ $\mathrm{mL}$ ) (correlation cofficient $\mathrm{r}=0.9998$ ) with the detection limit of $1.1 \times 10^{-8} \mathrm{molL}^{-1}(2.5 \mathrm{ng} / \mathrm{mL})$. It is six times lower than determination in reaction system without europium(III) ions [18].

\section{Interference}

The effect of some common inorganic ion and excipient species on the determination of $2.0 \times 10^{-7} \mathrm{molL}^{-1}$ naproxen solution was studied. The tolerance limit was taken as the recovery in the range $95 \%-105 \%$. The tolerance ratios were as follows: 5000-fold for indomethacin, ibuprofen, $\mathrm{K}(\mathrm{I}), \mathrm{Na}$ (I), $\mathrm{Mg}(\mathrm{II}), \mathrm{Ca}(\mathrm{II}) ; \mathrm{Zn}(\mathrm{II}) ; \mathrm{NO}_{3}{ }^{-}, \mathrm{SO}_{4}{ }^{2-}$; 500 -fold for $\mathrm{CO}_{3}{ }^{2-}$; 100-fold for $\mathrm{Fe}$ (III) starch, glycine, glucose; and 30-fold for
$\mathrm{Fe}(\mathrm{II})$. These tolerance ratios were higher than in system without europium(III) ions [18].

\section{Applications}

The proposed method was applied to the determination of Naproxen in commercially available pharmaceuticals. The obtained results are shown in Table 1. As can be seen, there are no significant differences between the labeled values and those obtained by the suggested method. A mean recovery values were in the range $98-104 \%$.

The accuracy studies for the determination of naproxen in human urine were conducted with three known concentrations of the compound. Results of recovery studies for urine are given in Table 2. Each value represents the mean of five measurements.

\section{Conclusion}

The reaction system NSAID-Ce(IV) belongs to the group systems generating ultra-weak emission characteristic for excited carbonyl species formed as a result of NSAID oxidation. The presence of $\mathrm{Eu}(\mathrm{III})$ ions into the systems of IB-Ce(IV) and IM-Ce(IV) did not influence on CL intensity, however the $\mathrm{Eu}(\mathrm{III})$ ions are effective activators in the NP-Ce(IV) system. The CL reaction system of NP$\mathrm{Ce}(\mathrm{IV})-\mathrm{Eu}(\mathrm{III})$, as these studies have shown, can be analytically useful. This method gives a lower detection limit and a large tolerance of on the presence of inorganic ion and excipient species compared with the NP-Ce(IV) system. The proposed chemiluminescent method, based on emission of the $\mathrm{Eu}(\mathrm{III})$ ions in the NP-Ce(IV)-Eu(III) system, is simple, accurate and precise and allows the determination of naproxen in pharmaceutical preparations and in human urine.

Acknowledgments Financial support from the Polish Ministry of Science and Higher Education; Grant NN204 028236 is gratefully acknowledged.
Table 2 Determination of naproxen. in human urine with the proposed CL method

\begin{tabular}{lccc}
\hline Sample & Added $^{\mathrm{a}}(\mu \mathrm{g} / \mathrm{ml})$ & Found \pm SD $((\mu \mathrm{g} / \mathrm{ml})$ & Recovery \pm SD $(\%)$ \\
\hline Urine-1 & 2 & $2.04 \pm 0.04$ & $102 \pm 2$ \\
& 4 & $4.02 \pm 0.06$ & $100.5 \pm 1.5$ \\
Urine-2 & 10 & $9.82 \pm 0.16$ & $98.2 \pm 1.6$ \\
& 2 & $1.98 \pm 0.04$ & $99 \pm 2$ \\
& 6 & $6.02 \pm 0.07$ & $100.3 \pm 1.2$ \\
& 14 & $14.30 \pm 0.15$ & $102.1 \pm 1.1$ \\
\hline
\end{tabular}


Open Access This article is distributed under the terms of the Creative Commons Attribution Noncommercial License which permits any noncommercial use, distribution, and reproduction in any medium, provided the original author(s) and source are credited.

\section{References}

1. Vane JR, Botting RM (1995) New insights into the mode of action of anti-inflammatory drugs. Inftamm Res 44(1):1-10

2. Telyuk OI, Beltyukova SV, Yegorova AV, Yagodkin BN (2007) Complex compounds of terbium(III) with some are non-steroidal anti-inflammatory drugs and their analytical applications. J Anal Chem 62(4):330-335

3. Li D, Du J, Lu J (2008) Europium(III)-senstized chemiluminescence determination of ibuprofen in pharmaceutical preparations and biological fluids. Anal Letters 41(8):1366-1374

4. Kaczmarek M, Lis S (2009) Chemiluminescence determination of tetracyclines using Fenton system in the presence europium(III) ions. Anal Chim Acta 639(1-2):96-100

5. Al-Kindy SMZ, Suliman FEO (2007) Determination of ibuprofen in pharmacutical formulations using time-resolved terbium-sensitizied luminescence. Luminescence 22(4):294301

6. Gámiz-Gracia L, García-Campaña AM, Huertas-Pérez JF, Lara FJ (2009) Chemiluminescence detection in liquid chromatography: Applications to clinical, pharmaceutical, environmental and food analysis-A review. Anal Chim Acta 640(1-2): $7-28$

7. Kaczmarek M, Lis S (2006) Luminescence characterization of the reaction system Histidin $-\mathrm{KBrO}_{3}-\mathrm{Tb}(\mathrm{III})-\mathrm{H}_{2} \mathrm{SO}_{4}$. J Fluorescence 16(6):825-830
8. Aresta A, Palmisano F, Zambonin CG (2005) Determination of naproxen in human urine by solid-phase microextraction coupled to liquid chromatography. J Pharm Biomed Anal 39(3-4):643-647

9. Malavolti NL, Pilosol D, Nieman TA (1985) Determination of cholesterol with a microporous membrane chemiluminescence cell with cholesterol oxidase in solution. Anal Chim Acta 170:199-207

10. Wang X, Zhao H, Nie L, Jin L, Zhang Z (2001) Europium sensitized chemiluminescence determination of rufloxacin. Anal Chim Acta 445(2):169-175

11. Staninski K, Kaczmarek M, Lis S, KomarD SA (2009) Spectral analysis in ultraweak emissions of chemi- and Electrochemluminescence systems. J Rare Earths 27(4):593-597

12. Ostakhov SS, Sharipov GL, Voloshin AI, Kazakov VP, Tolstikov GA (1986) Catalysis and sensitization of chemiluminescence at thermal decomposition of adamantylidene-adamantane-1,2-dioxetane by $\mathrm{Tb}$, $\mathrm{Eu}$ and Ru compounds. Dokl Akad Nauk SSSR 287:1165-1168

13. Lis S (2002) Luminescence studies of lanthanide(III) ions in solution. J Alloys Comp 341(1-2):45-50

14. Velázquez MM, Valero M, Rodrignez LJ, Costa SMB, Santos MA (1995) Hydrogen binding in a non-steroidal anti-inflammatory drug, Naproxen. J Photochem Photobiol B Biol 29(1):23-31

15. Tanner DD, Osman SAA (1987) Oxidative decarboxylation. on the mechanism of the potassium persulfate promoted decarboxylation reaction. J Org Chem 52(21):4689-4693

16. Bosca F, Martinez-Manez R, Miranda MA, Primo J, Soto J, Vano L (1992) Oxidative decarboxylation of naproxen. J Pharm Sci 81 (5):479-482

17. Valero M, Carrillo C (2004) Effect of binary and ternary polyethyleneglycol and/or $\beta$-cyclodextrin complexes on the photochemical and photosensitizing properties of naproxen. $\mathrm{J}$ Photochem Photobiol B Biol 74(2-3):151-160

18. Campiglio A (1998) Determination of naproxen with chemiluminescence detection. Analyst 123(7):1571-1574 